Article

\title{
Copigmentation with Chlorogenic and Ferulic Acid Affected Color and Anthocyanin Stability in Model Beverages Colored with Sambucus peruviana, Sambucus nigra, and Daucus carota during Storage
}

\author{
Nuryati P. Pangestu, Gonzalo Miyagusuku-Cruzado and M. Monica Giusti *(D) \\ Department of Food Science and Technology, The Ohio State University, 2015 Fyffe Rd, \\ Columbus, OH 43210-1007, USA; nuryati.pangestu@gmail.com (N.P.P.); \\ miyagusukucruzado.1@osu.edu (G.M.-C.) \\ * Correspondence: giusti.6@osu.edu; Tel.: +1-614-247-8016
}

Received: 23 September 2020; Accepted: 9 October 2020; Published: 16 October 2020

\begin{abstract}
The food industry is looking for alternatives to synthetic colorants. Anthocyanins (ACNs) are suitable replacements due to their color characteristics and potential health benefits. The application of sauco (Sambucus peruviana, SP) as a potential source of ACN-based colorants was evaluated and compared to elderberry (Sambucus nigra, SN) and an extract from purple carrots (PC). Color and pigment stability were evaluated using a model beverage system during eight weeks of storage. Copigmentation with chlorogenic acid (CGA) and ferulic acid (FA) were also evaluated. SP ACNs provided darker and more intense colors than those obtained with SN but less intense than those obtained with PC. Addition of CGA and FA resulted in significantly darker colors with higher chroma in beverages colored with SP and SN but not in beverages colored with PC. Copigmentation with FA reduced monomeric pigment half-lives for all ACN sources but increased the chroma half-lives of beverages colored with SP and SN, from 23 to 49 weeks, and from 23 to 55 weeks, respectively. Analyses using liquid chromatography coupled to photodiode array detection and mass spectrometry showed that interaction between non-acylated ACNs and FA resulted in the formation of pyranoanthocyanins. Overall, ACNs from non-acylated sources such as SP, in combination with FA, showed potential for commercial food applications.
\end{abstract}

Keywords: copigmentation; anthocyanins; pyranoanthocyanins; color stability

\section{Introduction}

Color is defined as a sensation perceived by an individual when light within the visible spectrum falls upon the retina. It plays a major role in the acceptability of foods, as consumers tend to use color as an indicator of flavor, safety, texture, and nutritional value [1]. For centuries, the food industry has used colorants to ensure uniformity or improve the original appearance of foods [2]. Interest and demand for colorants from natural sources have increased considerably because of legislative action and consumer concerns over the use of artificial additives in foods [1-3]. Some undesirable effects of synthetic food colorants are related to allergy, hypersensitivity, intolerance, and hyperactivity in children [3-5].

Anthocyanins (ACNs) are water-soluble pigments responsible for imparting attractive colors in plant tissues, including fruits, flowers and grains [6]. Additionally, ACN consumption has shown potential health benefits such as free radical scavenging and anti-inflammatory activity [7], lessening capillary permeability and fragility [8], obesity prevention [9], as well as anti-neoplasic and 
anti-tumor properties [10]. Therefore, the application of ACN-rich extracts as food colorants may provide both attractive colors and nutritional benefits.

Sambucus peruviana (SP) is a Peruvian elderberry, which has a pleasant flavor and is commonly known as sauco. SP ACN profile is composed by only non-acylated ACNs [11,12]. Sambucus nigra (SN) is an European elderberry containing non-acylated ACNs [13], whose pigments have been widely used as colorants for various foods and beverages such as juices, wines, jams, and canned fruits [14-17]. Typically, non-acylated ACNs show limited stability in food matrices [2]. However, addition of copigments can enhance pigment stability during storage [18], spray drying [19], thermal processing [20], and high-pressure processing [21]. Moreover, studies have shown that copigmentation with phenolic acids resulted in an improvement of color and color stability of ACN-rich extracts from fruits and berries in a wide variety of food matrices such as juices, purees, jams, and syrups [22-25]. Daucus carota or purple carrot (PC), contains ACNs with the same anthocyanidin as SN and SP; however, its major ACNs are acylated with hydroxycinnamic acids [26]. It has been reported that acylated ACNs have a higher stability during storage than their non-acylated counterparts [2].

Ferulic acid (FA) is a ubiquitous hydroxycinnamic acid that can be found in the seeds and leaves of a wide variety of food plants with multiple applications in the food industry such as a food preservative and a color protecting agent [27]. Moreover FA and compounds bearing a feruloyl moiety were shown to have anti-inflammatory, antidiabetic, and anticancer activity $[27,28]$. Chlorogenic acid (CGA) is one of the most available phenolic acids that can be found in abundance in coffee, tea, citrus fruits, and berries [29]. CGA can be used as a food additive due to its antimicrobial and antioxidant properties, and its ability to inhibit the degradation of other phytochemicals such as ACNs [30]. Moreover, CGA has been shown to have antidiabetic, anti-obesity, antioxidant, anti-inflammatory, and anti-hypertension effects upon consumption [29,30]. Therefore, due to their wide availability, many plant extracts can be used as natural sources for FA and CGA without further purification, acting not only as color stabilizing agents but also as bioactive natural extracts.

The prolonged interaction of ACNs with some phenolic compounds such as hydroxycinnamic acids can result in the formation of more stable ACN-derived pigments called pyranoanthocyanins (PACNs) [26]. These ACN-derived pigments are characterized by the presence of an extra pyran ring formed through the cycloaddition of a reactive adduct onto position $\mathrm{C}-4$ and the 5-OH group of the ACN [31]. PACN formation has not been reported to occur spontaneously in solutions containing acylated ACNs, thus requiring the addition of an exogenous cofactor to promote their formation, despite having a hydroxycinnamic acid present in the ACN structure [26]. Generally, these compounds have a different UV-Vis spectrum than their respective ACN predecessor along with an improved resistance to bleaching and enhanced stability during storage [32]. PACNs formed with hydroxycinnamic acids have stronger antioxidant and similar anti-inflammatory activities than their ACN counterparts [33,34]. These bioactive characteristics combined with their higher resistance to degradation under gastrointestinal conditions [35] may result in an enhanced bio-effectiveness and bioactivity of PACNs.

In this study, we evaluated the application of SP as a new source of ACN-based food colorant, using a beverage model system. The changes in color and pigment stability were measured during an eight-week storage period and compared model beverages colored with commercial extracts from SN and PC. Moreover, the effects on color and pigment stability of two types of copigment (CGA or FA) were also evaluated, as well as the possible formation of PACNs during storage.

\section{Materials and Methods}

\subsection{Materials}

\subsubsection{Chemicals}

Isosweet 100 high-fructose corn syrup was obtained from Tate \& Lyle (Decatur, IL, USA), potassium sorbate from Spectrum (Gardena, CA, USA), sodium benzoate from Alfa Aesar (Heysham, Lancaster, 
UK), and sodium bicarbonate from Sigma Chemical Co. (St. Louis, MO, USA). Citric acid, mass spectrometry (MS) grade water, acetonitrile, methanol, formic acid, hydrochloric acid, and high pressure liquid chromatography (HPLC) grade acetone were purchased from Fisher Scientific (Fair Lawn, NJ, USA). Chloroform and ethyl acetate were obtained from Mallinckrodt Chemicals (Phillipsburg, NJ, USA). CGA and FA were purchased from MP Biochemicals, LLC (Solon, OH, USA). All reagents were of analytical grade unless otherwise indicated.

\subsubsection{Plant Materials and ACN Extracts}

SP berries were harvested in Andahuaylas, Apurimac, Peru. Berries were washed, blended, and freeze-dried in a $4.5 \mathrm{~L}$ capacity Labconco freeze dryer (Kansas City, MO, USA) at $-48 \pm 2{ }^{\circ} \mathrm{C}$ at the laboratories of the Universidad Nacional Agraria La Molina in Lima, Peru. Dried samples were refrigerated at $4{ }^{\circ} \mathrm{C}$ and sent to the Ohio State University in Columbus, $\mathrm{OH}$, USA for further analyses. SN extract was donated by Artemis International Inc. (Fort Wayne, IN, USA), and PC extract was donated by Diana Vegetal (Antrain, France).

\subsection{Methods}

\subsubsection{ACN Extraction from SP}

ACNs were extracted following the methodology described by Rodriguez-Saona and Wrolstad [36]. Briefly, freeze-dried SP powdered berries were extracted by dispersing $20 \mathrm{~g}$ of powder with $50 \mathrm{~mL}$ of $0.01 \% \mathrm{HCl}$ acidified water $(v / v)$ overnight, and then blending the reconstituted powder with $50 \mathrm{~mL}$ of acetone for 3 min using a Waring blender. The slurry was then passed through a Whatman No. 4 filter paper using a Büchner Funnel. The cake was re-extracted using $70 \%$ aqueous acetone $(v / v)$ until all pigments had been extracted from the cake. The ACN-rich solution was then placed into a separatory funnel and partitioned with 2 volumes of chloroform. Solutions were gently mixed and let stand overnight at $4{ }^{\circ} \mathrm{C}$ to ensure adequate separation. The $\mathrm{ACN}$-rich aqueous top layer was collected, and residual acetone/chloroform was evaporated using a Büchi rotary evaporator (Büchi Laboratories, Postfach, Switzerland) at $40^{\circ} \mathrm{C}$ under vacuum. The solution was then brought to $100 \mathrm{~mL}$ in a volumetric flask using $0.01 \% \mathrm{HCl}$ acidified water $(v / v)$.

\subsubsection{ACN Semi-purification}

ACN semi-purification was performed according to the method described by Rodriguez-Saona and Wrolstad [36]. Briefly, samples were passed through a $C_{18}$ Sep-Pak cartridge (6 cc, $1 \mathrm{~g}$, Waters Corp, Milford, MA, USA), previously activated with methanol and $0.01 \% \mathrm{HCl}$ acidified water $(v / v)$. ACNs and other phenolics were adsorbed onto the cartridge, while sugars, acids and water-soluble compounds were eluted with two volumes of acidified water. Ethyl acetate was used to remove other phenolic compounds such as phenolic acids and flavonols. The adsorbed ACNs were then eluted with $0.01 \% \mathrm{HCl}$ acidified methanol $(v / v)$. The $\mathrm{ACN}$-rich methanolic extract was then concentrated using a rotary evaporator at $40^{\circ} \mathrm{C}$, and the pigments were redissolved in acidified water.

\subsubsection{Monomeric ACN and Molymeric Color Quantification}

The monomeric ACN content in $\mathrm{ACN}$-rich extracts and model beverages was determined using the $\mathrm{pH}$ differential method, and the percent of polymeric color was determined using indices for pigment degradation, color density and polymeric color [37]. A Shimadzu 2450 spectrophotometer (Shimadzu, Columbia, MD, USA) was used for spectral measurements at 420,520 and $700 \mathrm{~nm}$ with $1 \mathrm{~cm}$ pathlength disposable cuvettes. Pigment content was calculated as cyanidin-3-glucoside equivalents (cy-3-glu eq.), using a molecular weight of $449.3 \mathrm{~g} / \mathrm{mol}$ and an extinction coefficient of $26,900 \mathrm{~L} \mathrm{~mol}^{-1} \mathrm{~cm}^{-1}$. 


\subsubsection{Preparation of Model Beverage Systems}

Model beverages were prepared according to the method described by Rodriguez-Saona et al. [38]. Briefly, a $10^{\circ}$ Brix solution containing high fructose corn syrup, $0.1 \%$ potassium sorbate $(w / v)$, $0.1 \%$ sodium benzoate $(w / v)$, and $0.1 \mathrm{M}$ citric acid was prepared. The $\mathrm{pH}$ of the solution was adjusted to 3.5 with sodium bicarbonate when needed. ACNs were added to model beverages for a final concentration of $20 \mathrm{mg}$ cy-3glu eq./100 mL model beverage. CGA or FA were added as copigments in an ACN:copigment molar proportion of 1:10 as suggested by Rein and Heinonen [24].

\subsubsection{Storage Studies}

Ten milliliters of model beverages colored with ACNs with and without copigments were placed in glass vials, flushed with nitrogen, capped, and pasteurized in water at $85^{\circ} \mathrm{C}$ for $25 \mathrm{~min}$. Vials were stored in a $25^{\circ} \mathrm{C}$ incubator for eight weeks; during which, monomeric ACN content, percent of polymeric color, as well as color parameters were monitored. Measurements were conducted in triplicate every two weeks $(0,2,4,6$ and 8 weeks).

2.2.6. HPLC Coupled with Photodiode Array Detection and Electrospray MS (HPLC-PDA-ESI-MS) Analyses of Model Beverages Colored with ACNs

The ACN profile of model beverages was analyzed at 0,4 , and 8 weeks using an HPLC system equipped with two LC-20AD pumps, a SIL-20AC autosampler and an SPD-M20A photodiode array (PDA) detector coupled to a LCMS-2010 mass spectrometer (Shimadzu, Columbia, MD, USA). Briefly, $50 \mu \mathrm{L}$ of model beverage colored with SP or SN were injected to a reversed-phase $\mathrm{C}_{18}$ Allsphere ODS-2 column ( $5 \mu \mathrm{m}, 4.6 \times 250 \mathrm{~mm}$; Grace Davison Discovery Sciences, Deerfield, MA, USA) with a Symmetry 2 micro guard column $(4.6 \times 22 \mathrm{~mm}$; Waters Corp, MA, USA). Separation was achieved using a binary solvent system of $5 \%(v / v)$ formic acid in water (solvent $A$ ) and $100 \%$ acetonitrile (solvent $B$ ). A linear gradient from $5-15 \%$ B at $8 \mathrm{~min}, 15-20 \%$ B at $15 \mathrm{~min}, 20-50 \%$ B at $30 \mathrm{~min}, 50 \%$ B for $3 \mathrm{~min}$ and $50-5 \%$ B at $37 \mathrm{~min}$, was used at a flow rate of $1 \mathrm{~mL} / \mathrm{min}$. Due to the acylated nature of PC ACNs, a different column and gradient were used for chromatographic separation. Briefly, $50 \mu \mathrm{L}$ of model beverage colored with PC ACNs were injected to a reversed-phase Symmetry $C_{18}$ column $(3.5 \mu \mathrm{m}, 4.6 \times 150 \mathrm{~mm}$; Waters Corp., Milford, MA, USA) with a Symmetry 2 micro guard column $(4.6 \times 22 \mathrm{~mm}$; Waters Corp., Milford, MA, USA). Separation was achieved using a linear gradient from $5-20 \%$ B at $18 \mathrm{~min}, 20 \% \mathrm{~B}$ at $22 \mathrm{~min}, 20-5 \% \mathrm{~B}$ at $25 \mathrm{~min}$, and $5 \% \mathrm{~B}$ at $30 \mathrm{~min}$ at a flow rate of $0.8 \mathrm{~mL} / \mathrm{min}$.

A flow rate of $0.2 \mathrm{~mL} / \mathrm{min}$ was diverted to the mass spectrometer. Mass spectrometry analyses were conducted on a single quadrupole ion-tunnel mass spectrometer equipped with an electrospray ionization interface (ESI). Analyses were performed under positive ion mode with the following settings: nebulizing gas flow, $1.5 \mathrm{~L} / \mathrm{min}$; interface bias, $+4.5 \mathrm{kV}$; heat block temperature, $200{ }^{\circ} \mathrm{C}$; focus lens, $-2.5 \mathrm{~V}$; entrance lens, $-50 \mathrm{~V}$; pre-rod bias, $-3.6 \mathrm{~V}$; main-rod bias, $-3.5 \mathrm{~V}$; detector voltage, $1.5 \mathrm{kV}$; scan speed, $2000 \mathrm{amu} / \mathrm{sec}$. A full scan (total ion count, TIC) was performed with a mass range from 250-1200 $\mathrm{m} / \mathrm{z}$ and selected ion monitoring (SIM) was used to look for the molecular ions of the six most common ACN aglycones during the analysis ( $m / z 271,287,301,303,317,331)$. LCMS Solutions software (Version 3.0, Shimadzu, Columbia, MD, USA) was used to analyze and graphically represent the HPLC-PDA-ESI-MS data.

\subsubsection{Color Measurements}

An aliquot of each model beverage $(\approx 2 \mathrm{~mL})$ was transferred to a $2 \mathrm{~mm}$ pathlength precision cell made of optical glass (Hellma, Plainview, NY, USA) and read for CIELab parameters, lightness $\left(\mathrm{L}^{*}\right)$, chroma $\left(C^{*}\right)$ and hue angle $\left(h^{*}\right)$ using a Hunter Colorquest XE (HunterLab, Hunter Associates Laboratories Inc., Reston, VA, USA). The equipment was set for total transmittance, D65 illuminant, and a $10^{\circ}$ observer angle. 


\subsubsection{Statistical Analyses}

The results from color measurements, monomeric ACN quantification, and percent of polymeric color were subjected to regression analyses and one-way analysis of variance (ANOVA). Chroma and monomeric $\mathrm{ACN}$ concentration were plotted against time, and linear regression analyses were used to determine the adequacy of the degradation kinetic model. All statistical analyses were performed using SPSS 15.0 software (SPSS Inc., Chicago, IL, USA), and $p<0.05$ was considered statistically significant. All experiments were conducted in triplicate.

\section{Results and Discussion}

To assess the feasibility of using SP as a potential new source of ACN-based food colorants, the color characteristics and pigment stability of a model beverage colored with a semi-purified ACN extract from SP were evaluated over an eight-week storage period. These results were compared to a commercially used SN extract and a commercially available ACN extract from PC containing acylated ACNs.

\subsection{Initial Color Characteristics of Model Beverages}

The initial color characteristics of all model beverages are shown in Table 1. Non-acylated ACNs from SP provided a bright intense red color $\left(\mathrm{L}^{*}=56.79 \pm 0.04\right.$, chroma $=59.51 \pm 0.10$, hue angle $=15.53 \pm 0.07^{\circ}$ ) that were darker, more intense, and similar in hue to those obtained with the extract from SN $\left(L^{*}=69.13 \pm 0.17\right.$, chroma $=47.18 \pm 0.27$, hue angle $\left.=11.08 \pm 0.06^{\circ}\right)$. Model beverages colored with PC extract displayed a darker orange/red color at a higher hue angle with more color intensity $\left(L^{*}=44.11 \pm 0.03\right.$, chroma $=71.34 \pm 0.01$, hue angle $\left.=24.78 \pm 0.03^{\circ}\right)$ than the ones colored with SP. The effect of acylation on chroma values was significant $(p<0.05)$, as model beverages colored with acylated ACNs from PC had a higher chroma than those colored with extracts containing only non-acylated ACNs (SP and SN). Addition of copigments (CGA and FA) resulted in more intense colors with significantly higher chroma values $(p<0.05)$, and less yellow tones denoted by significantly lower hue angles $(p<0.05)$. The color of model beverages with non-acylated ACNs from SP and SN displayed a significantly darker color $(p<0.05)$ after copigment addition. However, the presence of copigments did not result in significant changes in the lightness $\left(\mathrm{L}^{*}\right)$ of model beverages colored with PC extract. Similar color enhancements have been reported for ACNs copigmented with phenolics, resulting in hyperchromic effects and color improvements due to a higher $\pi$-electron delocalization $[39,40]$. When comparing copigments, addition of CGA resulted in a more intense color than model beverages with FA. This was denoted by a significantly higher chroma for model beverages colored with SN $(p<0.05)$ and PC $(p<0.05)$ and copigmented with CGA. However, no significant differences in the chroma of model beverages colored with SP ACNs were observed when copigmented with either CGA or FA. Moreover, when compared against model beverages copigmented with FA, CGA addition resulted in a significantly higher hue angle for all colorant sources $(p<0.05)$.

Table 1. Initial color characteristics of model beverages colored with S. peruviana, S. nigra, and purple carrot extract with and without chlorogenic and ferulic acids as copigments.

\begin{tabular}{ccccc}
\hline Colorant & Copigment & L $^{*}$ & Chroma & Hue Angle \\
\hline \multirow{3}{*}{ S. peruviana } & No copigment & $56.79 \pm 0.04^{\mathrm{a}}$ & $59.51 \pm 0.10^{\mathrm{a}}$ & $15.53 \pm 0.07^{\mathrm{a}}$ \\
& Chlorogenic acid & $54.46 \pm 0.35^{\mathrm{b}}$ & $62.15 \pm 0.22^{\mathrm{b}}$ & $13.85 \pm 0.10^{\mathrm{b}}$ \\
& Ferulic acid & $54.70 \pm 0.53^{\mathrm{b}}$ & $61.53 \pm 0.54^{\mathrm{b}}$ & $12.52 \pm 0.33^{\mathrm{c}}$ \\
\hline \multirow{3}{*}{ S. nigra } & No copigment & $69.13 \pm 0.17^{\mathrm{a}}$ & $47.18 \pm 0.27^{\mathrm{a}}$ & $11.08 \pm 0.06^{\mathrm{a}}$ \\
& Chlorogenic acid & $65.16 \pm 0.11^{\mathrm{b}}$ & $52.66 \pm 0.14^{\mathrm{b}}$ & $7.95 \pm 0.08^{\mathrm{b}}$ \\
& Ferulic acid & $65.87 \pm 0.55^{\mathrm{b}}$ & $50.54 \pm 0.80^{\mathrm{c}}$ & $5.78 \pm 0.60^{\mathrm{c}}$ \\
\hline \multirow{2}{*}{ Purple carrot } & No copigment & $44.11 \pm 0.03^{\mathrm{a}}$ & $71.34 \pm 0.01^{\mathrm{a}}$ & $24.78 \pm 0.03^{\mathrm{a}}$ \\
extract & Chlorogenic acid & $43.79 \pm 0.18^{\mathrm{a}}$ & $70.38 \pm 0.18^{\mathrm{b}}$ & $22.84 \pm 0.20^{\mathrm{b}}$ \\
& Ferulic acid & $43.69 \pm 0.12^{\mathrm{a}}$ & $69.44 \pm 0.08^{\mathrm{c}}$ & $21.48 \pm 0.17^{\mathrm{c}}$ \\
\hline
\end{tabular}

Different letters indicate significant differences against model beverages without copigments for the same anthocyanin source. 


\subsection{Color Stability and Monomeric ACN Content in Model Beverages}

Results in Table 2 showed that for all colorant sources in this study, there was a significant decrease in chroma and monomeric ACN content over time $(p<0.01)$, despite the presence of copigments. It has been widely reported that colorants from natural sources fade away or lose color during storage, regardless of the type of pretreatment they were subjected to $[17,41,42]$. In model beverages without copigments, results showed that after eight weeks, the chroma for beverages colored with PC was significantly higher than that observed for SP and SN $(p<0.01$, data not shown). Regression analyses for model beverages colored with SP, SN or PC ACNs, showed that color degradation and monomeric ACN decrease followed a zero-order degradation kinetic model. Moreover, results showed that this behavior was not affected by the presence of a copigment. This is consistent with previous studies reporting similar degradation models for acylated ACNs from purple sweet potato [43], purple corn [44], and red radish [45]. Literature has shown that ACN acylation improves the color and stability of the pigment, mostly due to intramolecular copigmentation, with the anthocyanidin acting as a chromophore and the acyl group as electron-donor copigments $[2,46,47]$. However, results seem to indicate that acylation did not seem to modify the degradation model, but only the degradation speed.

Table 2. Degradation models and half-lives of color chroma and monomeric anthocyanins in model beverages with and without copigments.

\begin{tabular}{|c|c|c|c|c|c|c|c|}
\hline \multirow{2}{*}{ Colorant } & \multirow{2}{*}{ Copigment } & \multicolumn{3}{|c|}{ Chroma } & \multicolumn{3}{|c|}{ Monomeric Anthocyanins } \\
\hline & & Equation & $\begin{array}{l}\text { Half-Life } \\
\text { (weeks) }\end{array}$ & $R^{2}$ & Equation & $\begin{array}{l}\text { Half-Life } \\
\text { (days) }\end{array}$ & $R^{2}$ \\
\hline \multirow{3}{*}{ S. peruviana } & No copigment & $\begin{aligned} y & =-0.039 x \\
& +1.775\end{aligned}$ & 23 & 1.00 & $\begin{aligned} y & =-0.098 x \\
& +1.320\end{aligned}$ & 47 & 0.99 \\
\hline & $\begin{array}{l}\text { Chlorogenic } \\
\text { acid }\end{array}$ & $\begin{aligned} y & =-0.039 x \\
& +1.802\end{aligned}$ & 23 & 1.00 & $\begin{aligned} y & =-0.097 x \\
& +1.327\end{aligned}$ & 47 & 1.00 \\
\hline & Ferulic acid & $\begin{aligned} y & =-0.018 x \\
& +1.769\end{aligned}$ & 49 & 0.90 & $\begin{aligned} y & =-0.071 x \\
& +1.279\end{aligned}$ & 30 & 0.99 \\
\hline \multirow{3}{*}{ S. nigra } & No copigment & $\begin{aligned} y & =-0.037 x \\
& +1.685\end{aligned}$ & 23 & 0.97 & $\begin{aligned} y & =-0.071 x \\
& +1.279\end{aligned}$ & 63 & 0.98 \\
\hline & $\begin{array}{l}\text { Chlorogenic } \\
\text { acid }\end{array}$ & $\begin{aligned} y & =-0.041 x \\
& +1.739\end{aligned}$ & 21 & 0.98 & $\begin{aligned} y & =-0.072 x \\
& +1.274\end{aligned}$ & 62 & 0.99 \\
\hline & Ferulic acid & $\begin{aligned} y & =-0.015 x \\
& +1.683\end{aligned}$ & 55 & 0.85 & $\begin{aligned} y & =-0.146 x \\
& +1.245\end{aligned}$ & 29 & 0.99 \\
\hline \multirow{3}{*}{$\begin{array}{l}\text { Purple carrot } \\
\text { extract }\end{array}$} & No copigment & $\begin{aligned} y & =-1.414 x \\
& +72.213\end{aligned}$ & 26 & 0.92 & $\begin{aligned} y & =-1.257 x \\
& +20.154\end{aligned}$ & 56 & 0.97 \\
\hline & $\begin{array}{l}\text { Chlorogenic } \\
\text { acid }\end{array}$ & $\begin{array}{c}y=-1.626 x \\
+71.143\end{array}$ & 22 & 0.89 & $\begin{array}{c}y=-1.237 x \\
+20.125\end{array}$ & 58 & 0.95 \\
\hline & Ferulic acid & $\begin{aligned} y & =-1.865 x \\
& +71.035\end{aligned}$ & 19 & 0.90 & $\begin{aligned} y & =-1.723 x \\
& +18.451\end{aligned}$ & 38 & 0.98 \\
\hline
\end{tabular}

Results in Table 2 also showed that, in the absence of copigments, the half-life of the chroma of model beverages colored with SP and SN was similar (23 weeks), but shorter than the half-life of beverages colored with acylated ACNs form PC (26 weeks). Copigmentation of non-acylated ACNs with FA significantly decreased the degradation rate of the chroma $(p<0.01)$, thus extending their half-life from 23 to 49 weeks for SP, and from 23 to 55 weeks for SN. However, this effect was not observed in model beverages colored with PC, where addition of FA resulted in a decreased half-life of the chroma from 26 to 19 weeks. This behavior could be explained by previous literature that has shown that copigmentation of acylated ACNs with hydroxycinnamic acids resulted in a lower color stability, as it was hypothesized that the protective intramolecular mechanism of acylated ACNs was disrupted by exogenous ferulic and caffeic acid $[39,48]$. Nonetheless, this disrupting effect was not found for other types of phenolic acids such as gallic acid [39], and in this study it seems to be the case for CGA. Interestingly, results in Table 2 showed that in model beverages colored with SP or SN, 
the increased chroma stability showed by beverages copigmented with FA did not correlate with the shorter half-life of their monomeric ACN content.

\subsection{Polymeric ACN Content}

Results in Figure 1 showed a decrease in the monomeric ACN content in model beverages along with an increasing content of polymeric pigments over time. The effect of acylation on polymeric ACN content was significant, as model beverages colored with the PC extract showed a lower polymeric ACN content than those colored with non-acylated pigments $(p<0.05)$. On average over time, there was no significant difference in the polymeric ACN content between model beverages colored with SP and those colored with SN $(p>0.05)$. Results showed that copigmentation with FA resulted in a significantly faster degradation of monomeric $\mathrm{ACNs}(p<0.05)$ and a higher polymeric ACN content $(p<0.01)$. Unlike with FA, no significant differences in polymeric pigment content were observed between model beverages copigmented with CGA and those without copigment $(p>0.05)$. Studies have shown that monomeric ACN degradation usually resulted in the formation of polymeric pigments $[25,49,50]$. However, they also reported that this monomeric ACN degradation should result in a significant decrease in color intensity (chroma), which is not the case of model beverages colored with non-acylated ACNs copigmented with FA. Taken together, these results seem to indicate the presence of an $\mathrm{ACN}$-derived pigment that will form over time with $\mathrm{FA}$, that will not lose color at $\mathrm{pH}$ 4.5 when using the $\mathrm{pH}$ differential method for quantification of monomeric ACNs, and that will not bleach easily with sodium bisulfite.
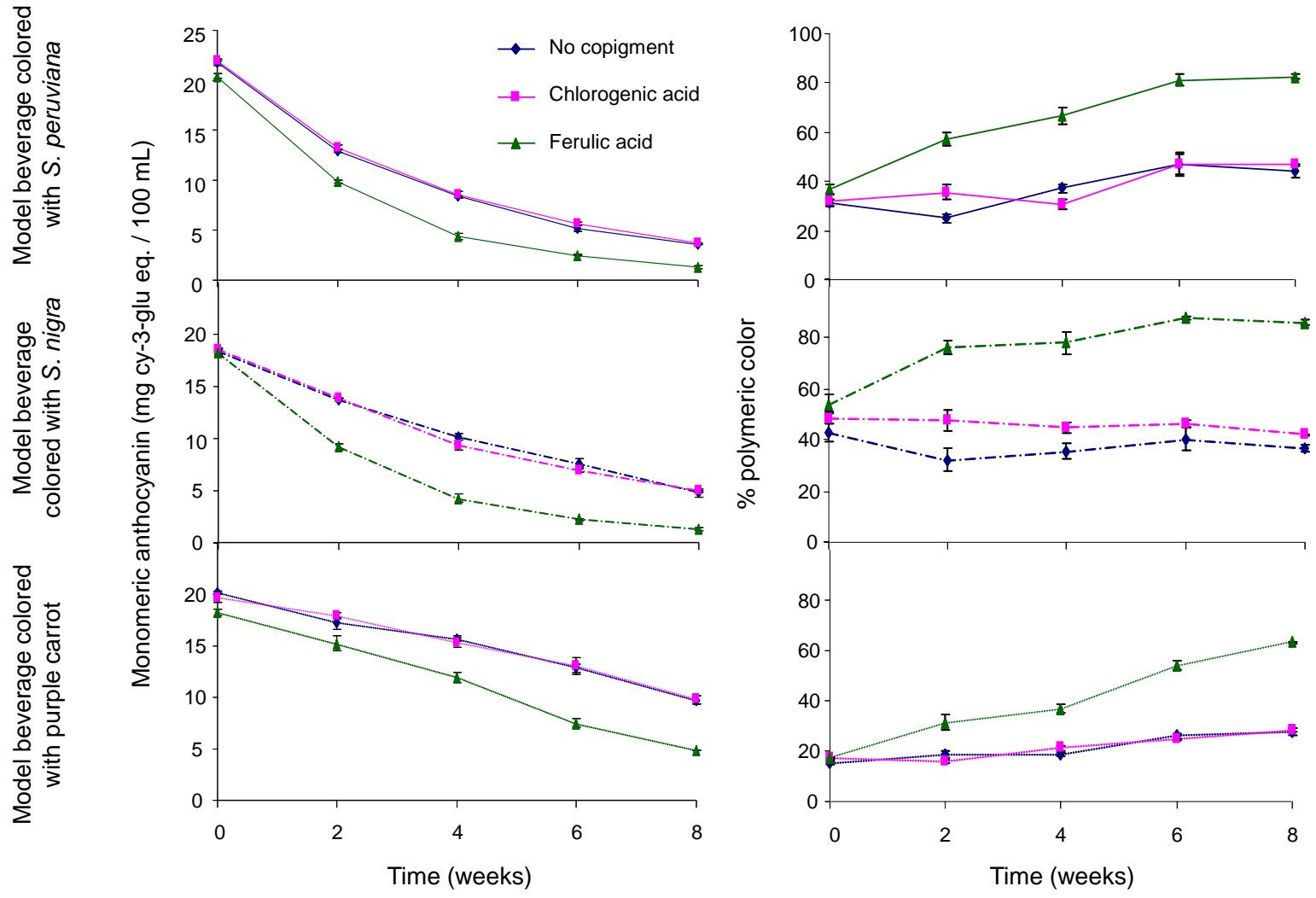

Figure 1. Effect of copigmentation on the monomeric anthocyanin content (left) and percent of polymeric color (right) in model beverages colored with S. peruviana (upper), S. nigra (middle), and purple carrot (lower). Model beverages with no copigment (blue line), with chlorogenic acid (pink line), and with ferulic acid (green line). 


\subsection{HPLC-PDA-ESI-MS Analysis of Pigments in Model Beverages}

To determine the ACN profile of model beverages and changes in its composition over time, HPLC-PDA-ESI-MS analyses were conducted at the start of the experiment, and after four, and eight weeks of storage. Results in Figure 2 and Table 3 showed the presence of three major ACNs in model beverages colored with SP, cyanidin-3-lathyroside (peak 1), cyanidin-3-sambubioside (peak 2), and cyanidin-3-glucoside (peak 3). This is consistent with two previous reports on the composition of SP ACN profile [11,12]. In the case of model beverages colored with SN, three major ACNs were found, cyanidin-3-sambubioside-5-glucoside (peak 1'), cyanidin-3-sambubioside (peak 2), and cyanidin-3-glucoside (peak 3). These results are similar to one previously reported for SN [51].

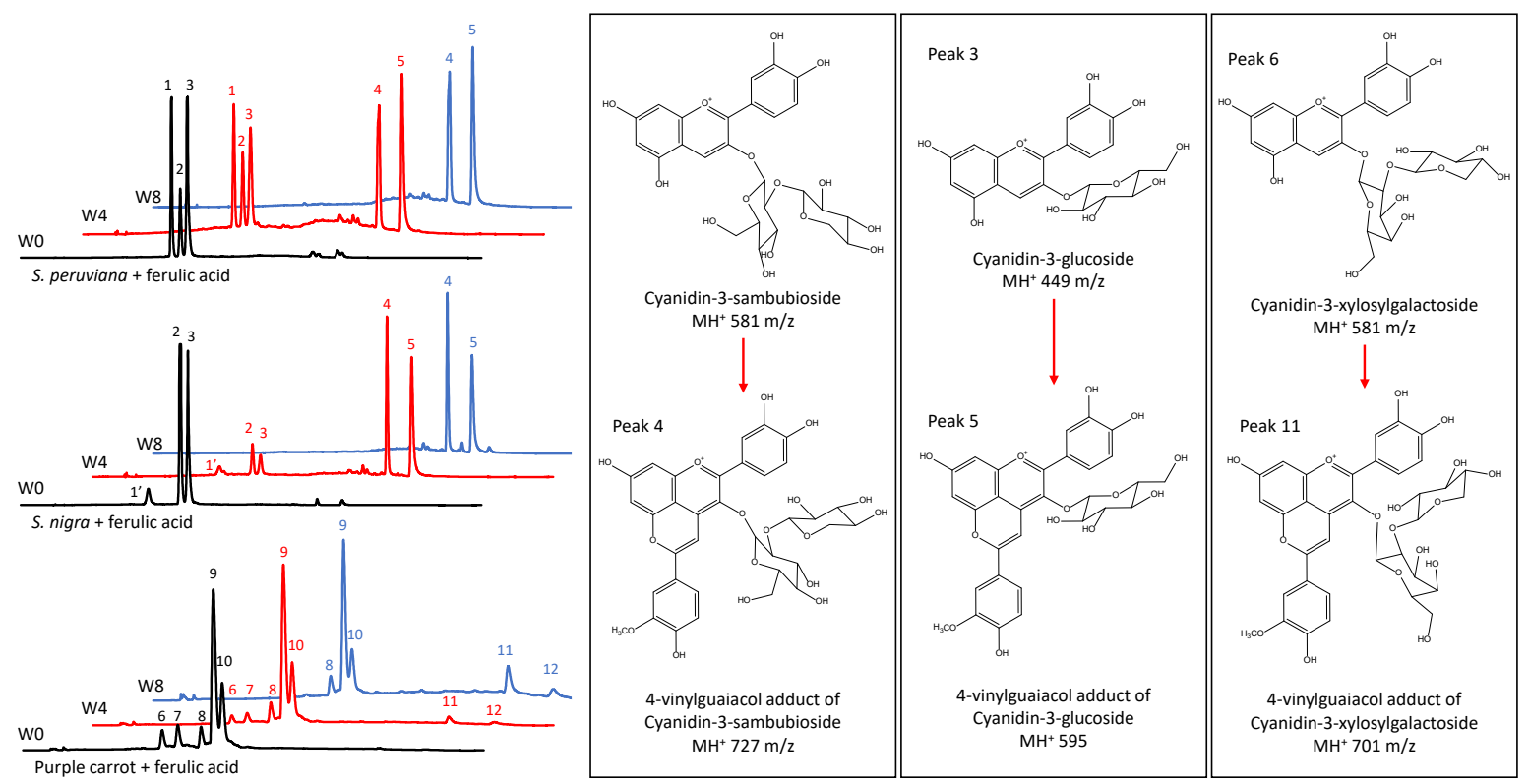

Figure 2. Anthocyanin high pressure liquid chromatography coupled with photodiode array detection (HPLC-PDA) profile of model beverages colored with anthocyanins and copigmented with ferulic acid at week 0 (W0, black line), week 4 (W4, red line) and week 8 (W8, blue line). Model beverages colored with S. peruviana (upper), S. nigra (middle), and purple carrot (lower).

Table 3. HPLC-PDA with electrospray mass spectrometry characterization and peak area percentage of anthocyanin (ACN) and anthocyanin-derived pigments in model beverages colored with S. peruviana, S. nigra, and purple carrot before (W0) and after eight weeks of storage (W8). CGA: chlorogenic acid, FA: ferulic acid.

\begin{tabular}{|c|c|c|c|c|c|c|c|c|}
\hline \multirow{2}{*}{ Peak } & \multirow{2}{*}{ ID } & \multirow{2}{*}{$m / z$} & \multicolumn{2}{|c|}{ ACN Only } & \multicolumn{2}{|c|}{ CGA } & \multicolumn{2}{|c|}{ FA } \\
\hline & & & Wo & W8 & Wo & W8 & Wo & W8 \\
\hline \multicolumn{9}{|c|}{ In model beverages colored with S. peruviana } \\
\hline 1 & Cyanidin-3-lathyroside & 581,287 & 32 & 37 & 34 & 37 & 34 & 0 \\
\hline 2 & Cyanidin-3-sambubioside & 581,287 & 23 & 26 & 21 & 26 & 17 & 0 \\
\hline 3 & Cyanidin-3-glucoside & 449,287 & 45 & 37 & 45 & 36 & 46 & 0 \\
\hline 4 & $\begin{array}{c}\text { Vinylguaiacol adduct of } \\
\text { cyanidin-3-sambubioside and vinylguaiacol } \\
\text { adduct of cyanidin-3-lathyroside }\end{array}$ & 727 & - & - & - & - & 2 & 45 \\
\hline 5 & $\begin{array}{l}\text { Vinylguaiacol adduct of } \\
\text { cyanidin-3-glucoside }\end{array}$ & 595 & - & - & - & - & 2 & 54 \\
\hline
\end{tabular}


Table 3. Cont.

\begin{tabular}{|c|c|c|c|c|c|c|c|c|}
\hline \multirow{2}{*}{ Peak } & \multirow{2}{*}{ ID } & \multirow{2}{*}{$m / z$} & \multicolumn{2}{|c|}{ ACN Only } & \multicolumn{2}{|c|}{ CGA } & \multicolumn{2}{|c|}{ FA } \\
\hline & & & Wo & W8 & Wo & W8 & Wo & W8 \\
\hline \multicolumn{9}{|c|}{ In model beverages colored with S. nigra } \\
\hline $1^{\prime}$ & Cyanidin-3-sambubioside-5-glucoside & 744,287 & 6 & 14 & 8 & 28 & 7 & 0 \\
\hline 2 & Cyanidin-3-sambubioside & 581,287 & 50 & 36 & 58 & 40 & 52 & 0 \\
\hline 3 & Cyanidin-3-glucoside & 449,287 & 44 & 31 & 34 & 32 & 38 & 0 \\
\hline 4 & $\begin{array}{l}\text { Vinylguaiacol adduct of } \\
\text { cyanidin-3-sambubioside }\end{array}$ & 727 & - & - & - & - & 1 & 50 \\
\hline 5 & $\begin{array}{l}\text { Vinylguaiacol adduct of } \\
\text { cyanidin-3-glucoside }\end{array}$ & 595 & - & - & - & - & 1 & 50 \\
\hline \multicolumn{9}{|c|}{ In model beverages colored with purple carrot } \\
\hline 6 & Cyanidin-3-xylosyl-galactoside & 581,287 & 6 & 3 & 6 & 3 & 5 & 1 \\
\hline 7 & Cyanidin-3-xylosyl-glucosyl-galactoside & 744,287 & 8 & 2 & 8 & 2 & 7 & 1 \\
\hline 8 & $\begin{array}{l}\text { Cyanidin-3-xylosyl-glucosyl-galactoside } \\
\text { acylated with p-coumaric acid }\end{array}$ & 889,287 & 5 & 5 & 5 & 5 & 5 & 6 \\
\hline 9 & $\begin{array}{l}\text { Cyanidin-3-xylosyl-glucosyl-galactoside } \\
\text { acylated with ferulic acid }\end{array}$ & 919,287 & 56 & 64 & 56 & 66 & 57 & 54 \\
\hline 10 & $\begin{array}{l}\text { Cyanidin-3-xylosyl-glucosyl-galactoside } \\
\text { acylated with sinapic acid }\end{array}$ & 949,287 & 25 & 26 & 25 & 24 & 25 & 18 \\
\hline 11 & $\begin{array}{l}\text { Vinylguaiacol adduct of } \\
\text { cyanidin-3-xylosyl-galactoside }\end{array}$ & 701 & - & - & - & - & 0 & 13 \\
\hline 12 & $\begin{array}{l}\text { Vinylguaiacol adduct of } \\
\text { cyanidin-3-xylosyl-glucosyl-galactoside * }\end{array}$ & ND & - & - & - & - & 0 & 7 \\
\hline
\end{tabular}

ND: Not detected, asterisk $\left(^{*}\right)$ denotes tentative identification.

Results showed that the presence of a copigment did not affect the proportion of these ACNs during storage. However, in model beverages colored with SP and SN, the presence of FA as a copigment resulted in the formation of two new peaks (peak 4 and peak 5 in Figure 2) characterized by longer retention times. These shifts in the retention times are remarkably similar to the ones shown for pyruvic acid adducts of ACNs from SN [51]. Mass spectrometry results in Table 3 showed that peaks 4 and 5 are consistent with pyranoanthocyanins of $m / z$ of 727 and 595, respectively. A $m / z$ of 727 is consistent with a 4-vinylguaiacol adduct of cyanidin-3-sambubioside or cyanidin-3-lathyroside. These two peaks may have coeluted and, due to their equal $\mathrm{m} / \mathrm{z}$ and similar PDA absorption spectra, separation was not possible under our experimental conditions. Additionally, a $\mathrm{m} / \mathrm{z}$ of 595 is consistent with a 4-vinylguaiacol adduct of cyanidin-3-glucoside. Similar compounds have been previously reported and denominated pinotins or hydroxyphenyl-pyranoanthocyanins $[26,47,52]$. Results in Figure 2 also showed that five major ACNs were found in model beverages colored with PC extract. As shown in Table 3, these were identified as cyanidin-3-xylosyl-galactoside (peak 6), cyanidin-3-xylosyl-glucosyl-galactoside (peak 7), cyanidin-3-xylosyl-glucosyl-galactoside acylated with $p$-coumaric acid (peak 8), cyanidin-3-xylosyl-glucosyl-galactoside acylated with FA (peak 9), and cyanidin-3-xylosyl-glucosyl-galactoside acylated with sinapic acid (peak 10). Unlike with non-acylated ACNs from SP and SN, copigmentation of PC ACNs with FA did not result in an enhancement of color intensity (chroma) or stability. However, after eight weeks of storage, two small new peaks were detected by the PDA after chromatographic separation. These may also be pyranoanthocyanins formed from the two minor non-acylated ACNs initially present in the PC extract. Similar results were reported by Schwarz et al. [26], where pyranoanthocyanins from PC were observed after 3 months of storage. As shown in Table 3, peak 11 was tentatively identified as the 4-vinylguaiacol adduct of cyanidin-3-xylosyl-galactoside. However, the $\mathrm{m} / \mathrm{z}$ of peak 12 was not elucidated by the MS, 
but it was tentatively assigned as a 4-vinylguaiacol adduct of cyanidin-3-xylosyl-glucosyl-galactoside. Moreover, acylated ACNs from PC apparently were not capable of forming pyranoanthocyanins during the duration of this study. Overall, these results showed that prolonged ACN interaction with FA resulted in the formation of pyranoanthocyanins. These ACN-derived pigments have a strong color at $\mathrm{pH} 1$ and do not lose color at $\mathrm{pH} 4.5$ [32], which in our study resulted in an underestimation of the monomeric pigment content when using the $\mathrm{pH}$ differential method. Moreover, these pigments are resistant to bisulfite bleaching due to the unavailability of position $\mathrm{C} 4$ of the original ACN structure, preventing the nucleophilic attack of bisulfite [32], which in our study resulted in an overestimation of the polymeric content. The presence of pyranoanthocyanins and their formation over time may explain the changes in the color characteristics as wells as in monomeric and polymeric ACN content in model beverages colored with ACNs and copigmented with FA.

\section{Conclusions}

SP ACNs provided color characteristics and stability to model beverages, comparable to a commercially available ACN extract from SN. However, its color characteristics were not as strong as in beverages colored with a PC extract rich in acylated ACNs. Addition of CGA as a copigment improved the initial color of model beverages colored with SP ACNs. However, it did not affect beverage color or pigment stability during storage. Interestingly, copigmentation with FA resulted in a more stable color but with lower monomeric $\mathrm{ACN}$ content and higher polymeric pigment content, due to the formation of pyranoanthocyanins. Overall, ACNs from SP, in combination with FA, showed potential to be used for commercial food and beverage applications as a natural and appealing value-added product. Future studies will focus on the efficient production of hydroxyphenyl-pyranoanthocyanins and their potential use as food colorants in different food matrices.

Author Contributions: Conceptualization, N.P.P. and M.M.G.; methodology, N.P.P. and M.M.G.; validation, N.P.P. and M.M.G.; formal analysis, N.P.P. and M.M.G.; investigation, N.P.P. and M.M.G.; resources, M.M.G.; data curation, N.P.P., G.M.-C. and M.M.G.; writing—original draft preparation, N.P.P., G.M.-C. and M.M.G.; writing-review and editing, N.P.P., G.M.-C. and M.M.G.; visualization, N.P.P., G.M.-C. and M.M.G.; supervision, M.M.G.; project administration, N.P.P. and M.M.G.; funding acquisition, M.M.G. All authors have read and agreed to the published version of the manuscript.

Funding: This research was supported in part by the USDA National Institute of Food and Agriculture, Hatch Project OHO01423, Accession number 1014136.

Conflicts of Interest: The authors declare no conflict of interest.

\section{References}

1. Sigurdson, G.T.; Tang, P.; Giusti, M.M. Natural colorants: Food colorants from natural sources. Annu. Rev. Food Sci. Technol. 2017, 8, 261-280. [CrossRef] [PubMed]

2. Giusti, M.M.; Wrolstad, R.E. Acylated anthocyanins from edible sources and their applications in food systems. Biochem. Eng. J. 2003, 14, 217-225. [CrossRef]

3. McCann, D.; Barrett, A.; Cooper, A.; Crumpler, D.; Dalen, L.; Grimshaw, K.; Kitchin, E.; Lok, K.; Porteous, L.; Prince, E.; et al. Food additives and hyperactive behaviour in 3-year-old and 8/9-year-old children in the community: A randomised, double-blinded, placebo-controlled trial. Lancet 2007, 370, 1560-1567. [CrossRef]

4. Bateman, B.; Warner, J.O.; Hutchinson, E.; Dean, T.; Rowlandson, P.; Gant, C.; Grundy, J.; Fitzgerald, C.; Stevenson, J. The effects of a double blind, placebo controlled, artificial food colourings and benzoate preservative challenge on hyperactivity in a general population sample of preschool children. Arch. Dis. Child. 2004, 89, 506-511. [CrossRef] [PubMed]

5. Feingold, B.F. Hyperkinesis and learning disabilities linked to the ingestion of artificial food colors and flavors. J. Learn. Disabil. 1976, 9, 551-559. [CrossRef]

6. Wrolstad, R.E. Anthocyanin pigments-Bioactivity and coloring properties. J. Food Sci. 2004, 69. [CrossRef] 
7. Carvalho, F.B.; Gutierres, J.M.; Bohnert, C.; Zago, A.M.; Abdalla, F.H.; Vieira, J.M.; Palma, H.E.; Oliveira, S.M.; Spanevello, R.M.; Duarte, M.M.; et al. Anthocyanins suppress the secretion of proinflammatory mediators and oxidative stress, and restore ion pump activities in demyelination. J. Nutr. Biochem. 2015, 26, 378-390. [CrossRef]

8. Cohen-Boulakia, F.; Valensi, P.E.; Boulahdour, H.; Lestrade, R.; Dufour-Lamartinie, J.F.; Hort-Legrand, C.; Behar, A. In vivo sequential study of skeletal muscle capillary permeability in diabetic rats: Effect of anthocyanosides. Metabolism 2000, 49, 880-885. [CrossRef]

9. Tsuda, T.; Horio, F.; Uchida, K.; Aoki, H.; Osawa, T. Dietary cyanidin 3-O- $\beta$-D-glucoside-rich purple corn color prevents obesity and ameliorates hyperglycemia in mice. J. Nutr. 2003, 133, 2125-2130. [CrossRef]

10. Chen, P.N.; Chu, S.C.; Chiou, H.L.; Kuo, W.H.; Chiang, C.L.; Hsieh, Y.S. Mulberry anthocyanins, cyanidin 3-rutinoside and cyanidin 3-glucoside, exhibited an inhibitory effect on the migration and invasion of a human lung cancer cell line. Cancer Lett. 2006, 235, 248-259. [CrossRef]

11. Porras-Mija, I.; Chirinos, R.; García-Ríos, D.; Aguilar-Galvez, A.; Huaman-Alvino, C.; Pedreschi, R.; Campos, D. Physico-chemical characterization, metabolomic profile and in vitro antioxidant, antihypertensive, antiobesity and antidiabetic properties of Andean elderberry (Sambucus nigra subsp. peruviana). J. Berry Res. 2019, 10, 193-208. [CrossRef]

12. Paudel, L. High Field 1H Nuclear Magnetic Resonance (NMR) Spectroscopy Based Metabolomics and Complex Mixture Analysis by Multidimensional NMR and Liquid Chromatography-Mass Spectrometry (LC-MS). Ph.D. Thesis, The University of Akron, Akron, OH, USA, 2012.

13. Veberic, R.; Jakopic, J.; Stampar, F.; Schmitzer, V. European elderberry (Sambucus nigra L.) rich in sugars, organic acids, anthocyanins and selected polyphenols. Food Chem. 2009, 114, 511-515. [CrossRef]

14. Kaack, K.; Fretté, X.C.; Christensen, L.P.; Landbo, A.K.; Meyer, A.S. Selection of elderberry (Sambucus nigra L.) genotypes best suited for the preparation of juice. Eur. Food Res. Technol. 2008, 226, 843-855. [CrossRef]

15. Schmitzer, V.; Veberic, R.; Slatnar, A.; Stampar, F. Elderberry (Sambucus nigra L.) wine: A product rich in health promoting compounds. J. Agric. Food Chem. 2010, 58, 10143-10146. [CrossRef]

16. Zafrilla, P.; Valero, A.; García-Viguera, C. Stabilization of strawberry jam colour with natural colourants. Food Sci. Technol. Int. 1998, 4, 99-105. [CrossRef]

17. Kammerer, D.R.; Schillmöller, S.; Maier, O.; Schieber, A.; Carle, R. Colour stability of canned strawberries using black carrot and elderberry juice concentrates as natural colourants. Eur. Food Res. Technol. 2007, 224, 667-679. [CrossRef]

18. Chatham, L.A.; Howard, J.E.; Juvik, J.A. A natural colorant system from corn: Flavone-anthocyanin copigmentation for altered hues and improved shelf life. Food Chem. 2020, 310, 125734. [CrossRef]

19. Weber, F.; Boch, K.; Schieber, A. Influence of copigmentation on the stability of spray dried anthocyanins from blackberry. LWT Food Sci. Technol. 2017, 75, 72-77. [CrossRef]

20. Kanha, N.; Surawang, S.; Pitchakarn, P.; Regenstein, J.M.; Laokuldilok, T. Copigmentation of cyanidin 3-O-glucoside with phenolics: Thermodynamic data and thermal stability. Food Biosci. 2019, 30, 100419. [CrossRef]

21. Terefe, N.S.; Netzel, G.A.; Netzel, M.E. Copigmentation with Sinapic Acid Improves the Stability of Anthocyanins in High-Pressure-Processed Strawberry Purees. J. Chem. 2019, 2019. [CrossRef]

22. Wilska-Jeszka, J.; Korzuchowska, A. Anthocyanins and chlorogenic acid copigmentation-Influence on the colour of strawberry and chokeberry juices. Eur. Food Res. Technol. 1996, 203, 38-42. [CrossRef]

23. Dufour, C.; Sauvaitre, I. Interactions between anthocyanins and aroma substances in a model system. Effect on the flavor of grape-derived beverages. J. Agric. Food Chem. 2000, 48, 1784-1788. [CrossRef] [PubMed]

24. Rein, M.J.; Heinonen, M. Stability and Enhancement of Berry Juice Color. J. Agric. Food Chem. 2004, 52, 3106-3114. [CrossRef]

25. Sari, P.; Wijaya, C.H.; Sajuthi, D.; Supratman, U. Colour properties, stability, and free radical scavenging activity of jambolan (Syzygium cumini) fruit anthocyanins in a beverage model system: Natural and copigmented anthocyanins. Food Chem. 2012, 132, 1908-1914. [CrossRef]

26. Schwarz, M.; Wray, V.; Winterhalter, P. Isolation and identification of novel pyranoanthocyanins from black carrot (Daucus carota L.) juice. J. Agric. Food Chem. 2004, 52, 5095-5101. [CrossRef]

27. Kumar, N.; Pruthi, V. Potential applications of ferulic acid from natural sources. Biotechnol. Rep. 2014, 4, 86-93. [CrossRef] [PubMed] 
28. De Oliveira Silva, E.; Batista, R. Ferulic Acid and Naturally Occurring Compounds Bearing a Feruloyl Moiety: A Review on Their Structures, Occurrence, and Potential Health Benefits. Compr. Rev. Food Sci. Food Saf. 2017, 16, 580-616. [CrossRef]

29. Naveed, M.; Hejazi, V.; Abbas, M.; Kamboh, A.A.; Khan, G.J.; Shumzaid, M.; Ahmad, F.; Babazadeh, D.; FangFang, X.; Modarresi-Ghazani, F.; et al. Chlorogenic acid (CGA): A pharmacological review and call for further research. Biomed. Pharmacother. 2018, 97, 67-74. [CrossRef]

30. Santana-Gálvez, J.; Cisneros-Zevallos, L.; Jacobo-Velázquez, D.A. Chlorogenic Acid: Recent advances on its dual role as a food additive and a nutraceutical against metabolic syndrome. Molecules 2017, 22, 358. [CrossRef]

31. Mateus, N.; Silva, A.M.S.; Vercauteren, J.; De Freitas, V. Occurrence of anthocyanin-derived pigments in red wines. J. Agric. Food Chem. 2001, 49, 4836-4840. [CrossRef]

32. He, J.; Carvalho, A.R.F.; Mateus, N.; De Freitas, V. Spectral features and stability of oligomeric pyranoanthocyanin-flavanol pigments isolated from red wines. J. Agric. Food Chem. 2010, 58, 9249-9258. [CrossRef]

33. Peng, Y.; Zhang, H.; Liu, R.; Mine, Y.; McCallum, J.; Kirby, C.; Tsao, R. Antioxidant and anti-inflammatory activities of pyranoanthocyanins and other polyphenols from staghorn sumac (Rhus hirta L.) in Caco-2 cell models. J. Funct. Foods 2016, 20, 139-147. [CrossRef]

34. Sun, J.; Li, X.; Luo, H.; Ding, L.; Jiang, X.; Li, X.; Jiao, R.; Bai, W. Comparative Study on the Stability and Antioxidant Activity of Six Pyranoanthocyanins Based on Malvidin-3-glucoside. J. Agric. Food Chem. 2020, 68, 2783-2794. [CrossRef]

35. McDougall, G.J.; Fyffe, S.; Dobson, P.; Stewart, D. Anthocyanins from red wine-Their stability under simulated gastrointestinal digestion. Phytochemistry 2005, 66, 2540-2548. [CrossRef]

36. Rodriguez-Saona, L.E.; Wrolstad, R.E. Extraction, isolation, and purification of anthocyanins. Curr. Protoc. Food Anal. Chem. 2001, 7-17. [CrossRef]

37. Giusti, M.M.; Wrolstad, R.E. Characterization and measurement of anthocyanins by UV-visible spectroscopy. Curr. Protoc. Food Anal. Chem. 2001. [CrossRef]

38. Rodríguez-Saona, L.E.; Giusti, M.M.; Wrolstad, R.E. Color and pigment stability of red radish and red-fleshed potato anthocyanins in juice model systems. J. Food Sci. 1999, 64, 451-456. [CrossRef]

39. Qian, B.J.; Liu, J.H.; Zhao, S.J.; Cai, J.X.; Jing, P. The effects of gallic/ferulic/caffeic acids on colour intensification and anthocyanin stability. Food Chem. 2017, 228, 526-532. [CrossRef]

40. Klisurova, D.; Petrova, I.; Ognyanov, M.; Georgiev, Y.; Kratchanova, M.; Denev, P. Co-pigmentation of black chokeberry (Aronia melanocarpa) anthocyanins with phenolic co-pigments and herbal extracts. Food Chem. 2019, 279, 162-170. [CrossRef]

41. You, Y.; Li, N.; Han, X.; Guo, J.; Zhao, Y.; Liu, G.; Huang, W.; Zhan, J. Influence of different sterilization treatments on the color and anthocyanin contents of mulberry juice during refrigerated storage. Innov. Food Sci. Emerg. Technol. 2018, 48, 1-10. [CrossRef]

42. Sui, X.; Bary, S.; Zhou, W. Changes in the color, chemical stability and antioxidant capacity of thermally treated anthocyanin aqueous solution over storage. Food Chem. 2016, 192, 516-524. [CrossRef] [PubMed]

43. Li, J.; Song, H.; Dong, N.; Zhao, G. Degradation kinetics of anthocyanins from purple sweet potato (Ipomoea batatas L.) as affected by ascorbic acid. Food Sci. Biotechnol. 2014, 23, 89-96. [CrossRef]

44. Jing, P.; Giusti, M.M. Characterization of anthocyanin-rich waste from purple corncobs (Zea mays L.) and its application to color milk. J. Agric. Food Chem. 2005, 53, 8775-8781. [CrossRef] [PubMed]

45. Jing, P.; Zhao, S.J.; Ruan, S.Y.; Xie, Z.H.; Dong, Y.; Yu, L. Anthocyanin and glucosinolate occurrences in the roots of Chinese red radish (Raphanus sativus L.), and their stability to heat and pH. Food Chem. 2012, 133, 1569-1576. [CrossRef]

46. Zhao, C.L.; Yu, Y.Q.; Chen, Z.J.; Wen, G.S.; Wei, F.G.; Zheng, Q.; Wang, C.D.; Xiao, X.L. Stability-increasing effects of anthocyanin glycosyl acylation. Food Chem. 2017, 214, 119-128. [CrossRef]

47. Castañeda-Ovando, A.; de Pacheco-Hernández, M.L.; Páez-Hernández, M.E.; Rodríguez, J.A.; Galán-Vidal, C.A. Chemical studies of anthocyanins: A review. Food Chem. 2009, 113, 859-871. [CrossRef]

48. Eiro, M.J.; Heinonen, M. Anthocyanin color behavior and stability during storage: Effect of intermolecular copigmentation. J. Agric. Food Chem. 2002, 50, 7461-7466. [CrossRef] 
49. Sinela, A.; Rawat, N.; Mertz, C.; Achir, N.; Fulcrand, H.; Dornier, M. Anthocyanins degradation during storage of Hibiscus sabdariffa extract and evolution of its degradation products. Food Chem. 2017, 214, 234-241. [CrossRef]

50. Wallace, T.C.; Giusti, M.M. Determination of color, pigment, and phenolic stability in yogurt systems colored with nonacylated anthocyanins from Berberis boliviana L. as compared to other natural/synthetic colorants. J. Food Sci. 2008, 73. [CrossRef]

51. Mateus, N.; Oliveira, J.; Haettich-Motta, M.; De Freitas, V. New family of bluish pyranoanthocyanins. J. Biomed. Biotechnol. 2004, 2004, 299-305. [CrossRef]

52. De Freitas, V.; Mateus, N. Formation of pyranoanthocyanins in red wines: A new and diverse class of anthocyanin derivatives. Anal. Bioanal. Chem. 2011, 401, 1467-1477. [CrossRef]

Publisher's Note: MDPI stays neutral with regard to jurisdictional claims in published maps and institutional affiliations.

(C) 2020 by the authors. Licensee MDPI, Basel, Switzerland. This article is an open access article distributed under the terms and conditions of the Creative Commons Attribution (CC BY) license (http://creativecommons.org/licenses/by/4.0/). 